\title{
Effect of the Winemaking Practices and Aging on Phenolic Content of Smederevka and Chardonnay Wines
}

\author{
Violeta Ivanova $\cdot$ Borimir Vojnoski $\cdot$ Marina Stefova
}

Received: 4 May 2010 / Accepted: 16 March 2011 / Published online: 1 April 2011

(C) Springer Science+Business Media, LLC 2011

\begin{abstract}
Changes of the polyphenolic content, including total phenolics (TP), total flavonoids (TF), and total flavan3-ols $\left(\mathrm{TF}_{3 \text {-ols }}\right)$ determined by spectrophotometric methods, have been studied in Macedonian white wines from Vitis vinifera L. cv, Smederevka and Chardonnay, obtained under different vinifications and analyzed during 16 months of aging in bottles. Winemaking treatments for both varieties included an addition of two doses of $\mathrm{SO}_{2}(50$ and $100 \mathrm{mg} / \mathrm{L}$ ) and two commercial yeasts for fermentation, Vinalco and Levuline, both Saccharomyces cerevisiae species, in order to study the influence of $\mathrm{SO}_{2}$ and yeasts on the phenolic content of the wines. Comparing the two varieties, Chardonnay wines contained higher levels of total phenolics, flavonoids, and flavan-3-ols, probably as a result of the cultivar differences. Sulfur dioxide protected the phenolic oxidation, resulting in higher phenolic content in the wines with higher $\mathrm{SO}_{2}$ dose, while the yeast did not show significant influence on the total phenolics. During aging, the $\mathrm{TP}, \mathrm{TF}$, and $\mathrm{TF}_{3 \text {-ols }}$ in the wines from both
\end{abstract}

V. Ivanova $(\bowtie)$

University “Goce Delcev," Faculty of Agriculture,

Krste Misirkov bb,

2000 Stip, Republic of Macedonia

e-mail: violeta.ivanova@ugd.edu.mk

B. Vojnoski

Department for Enology, Institute of Agriculture,

Ss "Cyril and Methodius" University,

Aleksandar Makedonski bb,

1000 Skopje, Republic of Macedonia

M. Stefova

Faculty of Natural Sciences and Mathematics,

Institute of Chemistry, Ss "Cyril and Methodius" University,

Arhimedova 5,

1001 Skopje, Republic of Macedonia varieties decreased significantly up to the second month of storage and remained stable till the sixth month. The Student-Newman-Keuls test has been applied to ascertain possible significant differences between the studied wines, and a principal component analysis has been employed, showing separation and grouping of the wines according to the cultivar and time of aging.

Keywords Total phenolics · Total flavonoids · Total flavan-3-ols · Spectrophotometry · Smederevka . Chardonnay $\cdot$ Winemaking $\cdot \mathrm{SO}_{2} \cdot$ Yeast

\section{Introduction}

Phenolic compounds are considered as the main factors responsible for the quality of grapes and consequently for the corresponding wines. Wine phenolics belong to two main groups: nonflavonoids and flavonoids. The major nonflavonoid phenolic compounds in white wines are hydroxycinnamic acid derivatives (Lee and Jaworski 1987) which are easily oxidized components contributing to the browning of wines during aging (Cheynier et al. 1990). The most common flavonoids are flavan-3-ols and flavonols (and anthocyanins in red wines). Flavan-3-ols, mainly catechins and catechin-gallate polymers also produce a number of oxidation products that could be regarded as browning agents in white wines (Singleton and Cilliers 1995). Regarding the group of flavonols, quercetin derivatives are the main components present in the white wines (De Beer et al. 2005).

The flavonoid composition of white wines depends on the grape composition, on their extraction into the grape juice, and also, on the subsequent reactions occurring during the vinification, postfermentation treatments, and wine aging (Rayne et al. 2008). Usually, white wines are 
made without aeration in order to avoid extensive contact with oxygen, which, if present, may cause evolution effects during aging (Nevares et al. 2009) as browning of the wine and deterioration of the overall quality. Thus, for white wine production, maceration is kept to a minimum and seldom lasts more than a few hours. Usually, the grape juice runs freely from the crushed grapes followed by the immediate addition of $\mathrm{SO}_{2}$ in order to protect enzymatic oxidation. Controlled low temperatures $\left(14-18{ }^{\circ} \mathrm{C}\right)$ are usually applied for white wine production.

While there are reports in the literature about the concentration of polyphenols in white wines, mainly obtained using HPLC-DAD (Okamura and Watanabe 1981; Hurtado et al. 1997; Budić-Leto and Lovrić 2002; Jeffery et al. 2008), still there are no data on phenolics in white wines from the Republic of Macedonia. Therefore, it was considered that determination of total phenolics, total flavonoids, and total flavan-3-ols in white wines from the Smederevka and Chardonnay varieties, produced with two doses of $\mathrm{SO}_{2}$ and two yeasts would be of great importance for obtaining a general overview of their phenolic content and their changes during aging. For that purpose, spectrophotometric methods, being the most convenient, have been used for quantification since they require minimal sample preparation and analysis time. On the other hand, the applied spectrophotometric methods are readily available and applicable for routine quality control of wine during its production and storage.

\section{Materials and Methods}

\section{Chemicals}

The standard chemicals, $(+)$-catechin and gallic acid, and the reagent $p$-(dimethylamino)cinnamaldehyde ( $p$ DMACA), were purchased from Fluka (Switzerland) and the Folin-Ciocalteu reagent was from Merck (Germany). All the other used reagents were of analytical purity grade.

\section{Vinification Protocol}

Grapes from the Smederevka (Sm) and Chardonnay $(\mathrm{Ch})$ varieties were harvested at $\sim 20$ and $\sim 22^{\circ}$ Brix, respectively, and transported to the experimental cellar of the Department for Enology, Institute of Agriculture, Skopje, Republic of Macedonia. Grapes of both varieties were divided into four lots (15 kg for each lot) and were processed separately using a mechanical crusher/destemmer. Two doses of aqueous solution of potassium metabisulfite were immediately added to the Smederevka grape mashes and were mixed to give two lots with $50 \mathrm{mg} / \mathrm{L}$ (Sm50) and two lots with $100 \mathrm{mg} / \mathrm{L} \mathrm{SO}_{2}$ (Sm100). The same procedure was applied on the grape mashes of the Chardonnay variety, yielding also two lots
Ch50 and two lots Ch100. Musts were separated from the pomace by free running at $14-16{ }^{\circ} \mathrm{C}$, allowing minimum skin contact (about $5 \mathrm{~min}$ ), and collected in 25 -L plastic fermentation tanks. The grape juices were then inoculated with two yeasts (Saccharomyces cerevisiae) to start the fermentation of the musts: Vinalco (Bitola, Republic of Macedonia) and Levuline CHP (Bordeaux, France). The yeasts were rehydrated $(20 \mathrm{~g} / \mathrm{L}$ for Vinalco and $30 \mathrm{~g} / \mathrm{L}$ for Levuline) in water $\left(30{ }^{\circ} \mathrm{C}\right.$ for $\left.15 \mathrm{~min}\right)$, and the Macedonian yeast, Vinalco (Mac), was applied to two lots of both varieties containing $50 \mathrm{mg} / \mathrm{L} \mathrm{SO}_{2}$ (Sm50-Mac and Ch50-Mac) and to two other lots with $100 \mathrm{mg} / \mathrm{L} \mathrm{SO}_{2}$ (Sm100-Mac and Ch100$\mathrm{Mac})$. The French yeast, Levuline (Fr), was also applied to the remaining lots containing $50 \mathrm{~m} / \mathrm{L} \mathrm{SO}_{2}(\mathrm{Sm} 50-\mathrm{Fr}$ and $\mathrm{Ch} 50-\mathrm{Fr}$ ) and $100 \mathrm{mg} / \mathrm{L} \mathrm{SO}_{2}$ (Sm100-Fr and Ch100-Fr).

After finishing the fermentation, the wines were treated with $1 \mathrm{~g} / \mathrm{L}$ bentonite and cold stabilized at $-4{ }^{\circ} \mathrm{C}$ for a period of 2 weeks before bottling. The bottles were stored in a cellar, at a temperature between 12 and $15{ }^{\circ} \mathrm{C}$. In order to follow the changes of polyphenols during aging, the wines were analyzed after fermentation (after 10 days for Smederevka wines and after 7 days for Chardonnay wines), after 2, 6, and 16 months of aging in bottles. The labels of wines are presented in Table 1.

Determination of Total Phenolics, Flavonoids, and Flavan-3-ols

The total phenolic (TP) content of the wines has been determined using the Folin-Ciocalteu method (Slinkard and Singleton 1977; Ivanova et al. 2010). The total flavonoid (TF) content was evaluated according to a colorimetric assay with aluminum chloride (Zhishen et al. 1999). The content of total flavan-3-ols $\left(\mathrm{TF}_{3-\mathrm{ols}}\right)$ was measured using the $p$-DMACA method (Di Stefano et al. 1989).

\section{Statistical Methods}

Each wine was analyzed in triplicate. A statistical analysis including calculation of means, standard deviations, and principal component analysis (PCA) was performed using the TANAGRA 1.4.28 (Lyon, France) software. The StudentNewman-Keuls test of multiple comparison of the mean values for $\mathrm{TP}, \mathrm{TF}$, and $\mathrm{TF}_{3 \text {-ols }}$ was applied in order to ascertain possible significant differences between the studied white wines.

\section{Results and Discussion}

Influence of the Variety, $\mathrm{SO}_{2}$, and Yeast

Comparing the wines from both varieties, Smederevka and Chardonnay, produced under the same vinification con- 
Table 1 Labels for Smederevka and Chardonnay wine samples prepared under different vinifications $\left(\mathrm{SO}_{2}\right.$ doses and yeast) and analyzed during aging in bottles

Fermentation with Macedonian yeast

\begin{tabular}{|c|c|c|c|c|}
\hline \multirow[t]{2}{*}{ Phases of analysis } & \multicolumn{2}{|l|}{$50 \mathrm{mg} / \mathrm{L} \mathrm{SO}_{2}$} & \multicolumn{2}{|l|}{$100 \mathrm{mg} / \mathrm{L} \mathrm{SO}_{2}$} \\
\hline & Smederevka & Chardonnay & Smederevka & Chardonnay \\
\hline After fermentation & Sm50-Mac-end fermentation & Ch50-Mac-end fermentation & Sm100-Mac-end fermentation & Ch100-Mac-end fermentation \\
\hline After 2 months & Sm50-Mac-2m & Ch50-Mac-2m & Sm100-Mac-2m & Ch100-Mac-2m \\
\hline After 6 months & Sm50-Mac-6m & Ch50-Mac-6m & Sm100-Mac-6m & Ch100-Mac-6m \\
\hline After 16 months & Sm50-Mac-16m & Ch50-Mac-16m & Sm100-Mac-16m & Ch100-Mac-16m \\
\hline \multicolumn{5}{|c|}{ Fermentation with French yeast } \\
\hline \multirow[t]{2}{*}{ Phases of analysis } & $50 \mathrm{mg} / \mathrm{L} \mathrm{SO}_{2}$ & & $100 \mathrm{mg} / \mathrm{L} \mathrm{SO}_{2}$ & \\
\hline & Smederevka & Chardonnay & Smederevka & Chardonnay \\
\hline After fermentation & Sm50-Fr-end fermentation & Ch50-Fr-end fermentation & Sm100-Fr-end fermentation & Ch100-Fr-end fermentation \\
\hline After 2 months & Sm50-Fr-2m & Ch50-Fr-2m & Sm100-Fr-2m & Ch100-Fr-2m \\
\hline After 6 months & Sm50-Fr-6m & Ch50-Fr-6m & Sm100-Fr-6m & Ch100-Fr-6m \\
\hline After 16 months & Sm50-Fr-16m & Ch50-Fr-16m & Sm100-Fr-16m & Ch100-Fr-16m \\
\hline
\end{tabular}

$2 m 2$ months, $6 m 6$ months, $16 m 16$ months

ditions, in general, higher levels of $\mathrm{TP}, \mathrm{TF}$, and $\mathrm{TF}_{3 \text {-ols }}$ were determined in Chardonnay wines after the fermentation (Table 2). An analysis of variance revealed statistically significant differences in the content of total phenolics $(p<$ $0.001)$, flavonoids $(p<0.001)$, and flavan-3-ols $(p<0.001)$ between the wines from both varieties, which could be attributed to the cultivar-related differences. Furthermore, agricultural and environmental factors could also influence the content of TP, TF, and $\mathrm{TF}_{3-\text { ols }}$ in the wines. The results were in accordance with previous studies where the Chardonnay wine contained higher levels of phenolics compared to the Smederevka (Mitic et al. 2010). In addition, the results showed that Macedonian wines Smederevka and Chardonnay contained higher phenolic content compared to the other white varieties (Salacha et al. 2008; Katalinic et al. 2004; Chamkha et al. 2003; Singleton et al. 1999).

Sulfur dioxide acts as an effective antioxidant and prevents the oxidation of phenolics, resulting in a higher content of phenolic compounds in the wines with a higher dose of sulfur dioxide, as it was observed in this study too. Comparing the Smederevka wines fermented with the same yeast, but containing different $\mathrm{SO}_{2}$ doses (Table 2), generally a higher content of total phenolics, flavonoids, and flavan-3-ols could be seen in the wines containing a higher dose of $\mathrm{SO}_{2}$, likely because this agent prevented the phenolics oxidation. A similar trend was observed for TP, $\mathrm{TF}$, and $\mathrm{TF}_{3 \text {-ols }}$ of Chardonnay wines, except for the ones fermented with Macedonian yeast, for which a higher content of TFs and $\mathrm{TF}_{3 \text {-ols }}$ was found in the wines with a lower $\mathrm{SO}_{2}$ dose. This means that the addition of a higher amount of sulfur dioxide did not lead to a higher content of $\mathrm{TF}$ and $\mathrm{TF}_{3-\mathrm{ols}}$, as already found by Mayén et al. (1997).

With regard to the yeast influence, little is known about the ability of commercial Saccharomyces cerevisiae strains to affect the phenolic content of white wines during the fermentation process and wine aging. A current research

Table 2 Content of total phenolics, flavonoids, and flavan-3-ols of Smederevka and Chardonnay wines, produced under two $\mathrm{SO}_{2}$ doses $(50$ and $100 \mathrm{mg} / \mathrm{L}$ ) and two yeast strains (Vinalco and Levuline) analyzed after fermentation

\begin{tabular}{|c|c|c|c|c|c|c|c|c|}
\hline \multirow{2}{*}{$\begin{array}{l}\text { Vinification conditions } \\
\text { Wines }\end{array}$} & \multicolumn{2}{|l|}{$50-\mathrm{Mac}$} & \multicolumn{2}{|l|}{ 100-Mac } & \multicolumn{2}{|l|}{$50-\mathrm{Fr}$} & \multicolumn{2}{|l|}{$100-\mathrm{Fr}$} \\
\hline & $\mathrm{Sm}$ & $\mathrm{Ch}$ & $\mathrm{Sm}$ & $\mathrm{Ch}$ & $\mathrm{Sm}$ & $\mathrm{Ch}$ & $\mathrm{Sm}$ & $\mathrm{Ch}$ \\
\hline $\mathrm{TP}(\mathrm{mg} / \mathrm{L})$ & $417 \mathrm{a} \pm 2.22$ & $855 \mathrm{~b} \pm 8.01$ & $445 c \pm 5.83$ & $889 \mathrm{~d} \pm 6.91$ & $349 \mathrm{a} \pm 3.81$ & $848 b \pm 6.99$ & $533 c \pm 3.09$ & $975 \mathrm{~d} \pm 6.75$ \\
\hline $\mathrm{TF}(\mathrm{mg} / \mathrm{L})$ & $23.8 \pm 2.17$ & $321 \pm 2.61$ & $31.5 \pm 3.85$ & $126 \pm 1.83$ & $48.4 \pm 1.47$ & $244 \pm 4.57$ & $64.7 \pm 1.91$ & $303 \pm 3.03$ \\
\hline $\mathrm{TF}_{3 \text {-ols }}(\mathrm{mg} / \mathrm{L})$ & $4.03 b \pm 0.40$ & $39.6 \pm 2.42$ & $7.11 \mathrm{c} \pm 0.18$ & $24.7 \mathrm{~d} \pm 1.88$ & $6.18 \mathrm{~b} \pm 0.56$ & $25.0 \mathrm{a} \pm 1.74$ & $10.6 \mathrm{c} \pm 0.97$ & $23.3 \mathrm{a}, \mathrm{d} \pm 2.37$ \\
\hline
\end{tabular}

Values with the same letter(s) within a row are not significantly different at $p>0.05$ analyzed by the Student-Newman-Keul's test; 50-50 mg/L $\mathrm{SO}_{2}, 100-100 \mathrm{mg} / \mathrm{L} \mathrm{SO}_{2}$; results are presented as average from three replicates \pm standard deviation

Sm Smederevka; Ch Chardonnay; Mac Macedonian yeast, Vinalco; Fr French yeast, Levuline 


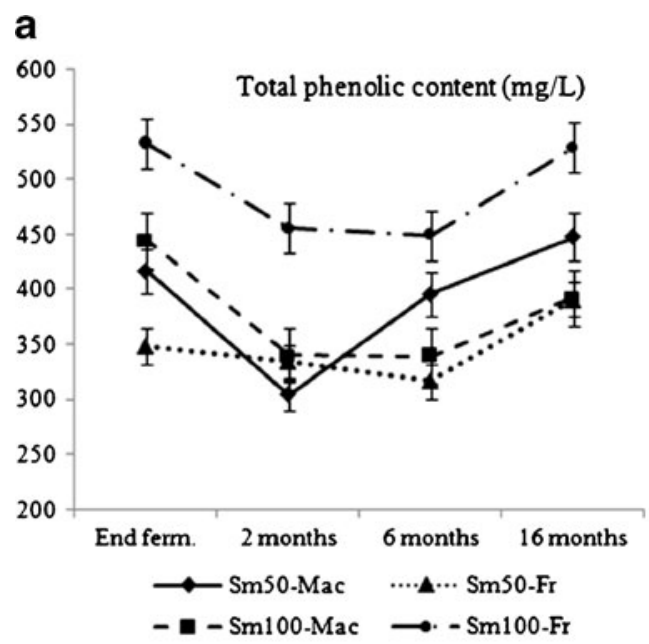

b

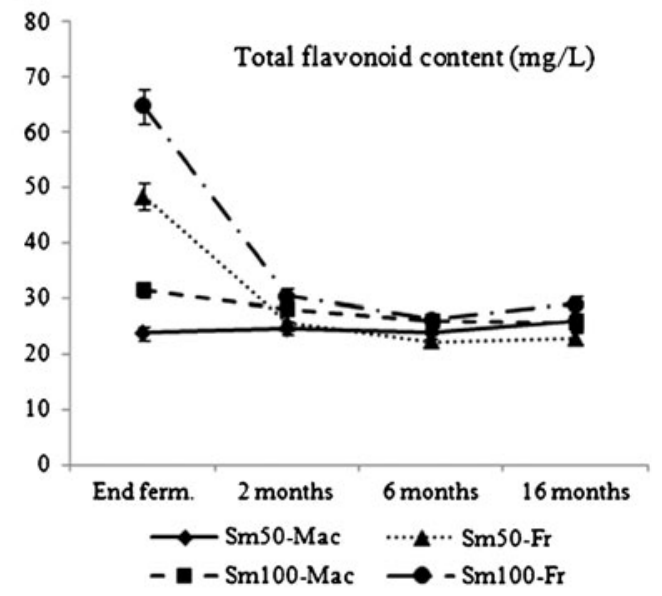

C

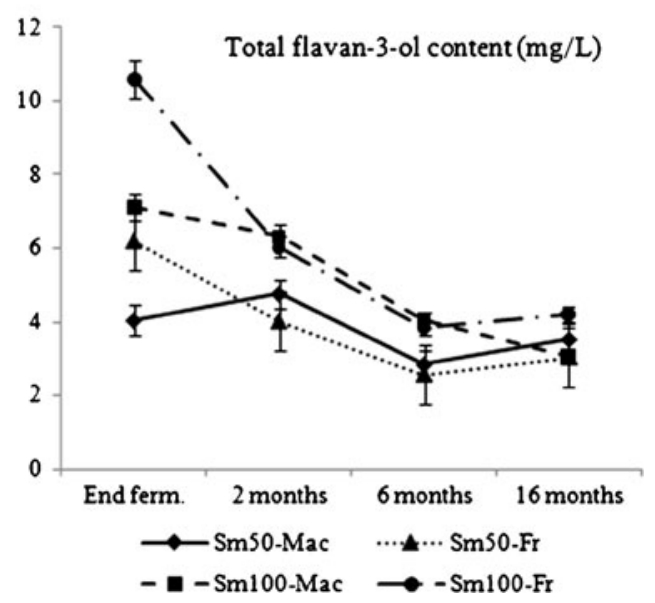

Fig. 1 Changes of a total phenolics, $\mathbf{b}$ total flavonoids, and $\mathbf{c}$ total flavan-3-ols in Smederevka wines fermented with Macedonian and French yeast, containing 50 and $100 \mathrm{mg} / \mathrm{L}$ of $\mathrm{SO}_{2}$ during storage: after fermentation, after 2, 6, and 16 months. Error bars represent standard deviations. Sm, Smederevka; Mac, Macedonian yeast; Fr, French yeast; $50-50 \mathrm{mg} / \mathrm{L} \mathrm{SO}_{2}, 100-100 \mathrm{mg} / \mathrm{L} \mathrm{SO}_{2}$

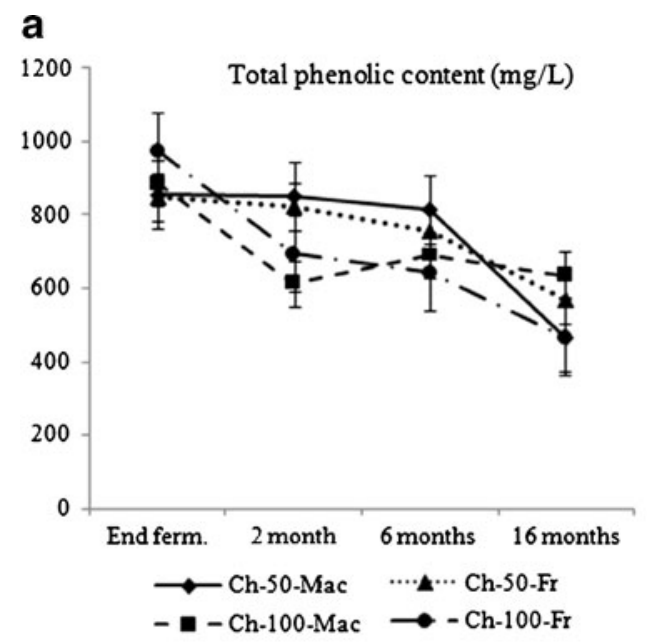

b

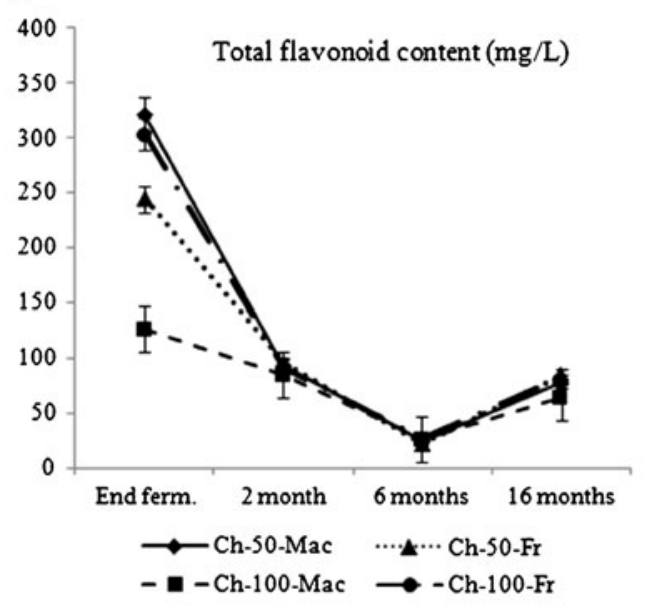

C

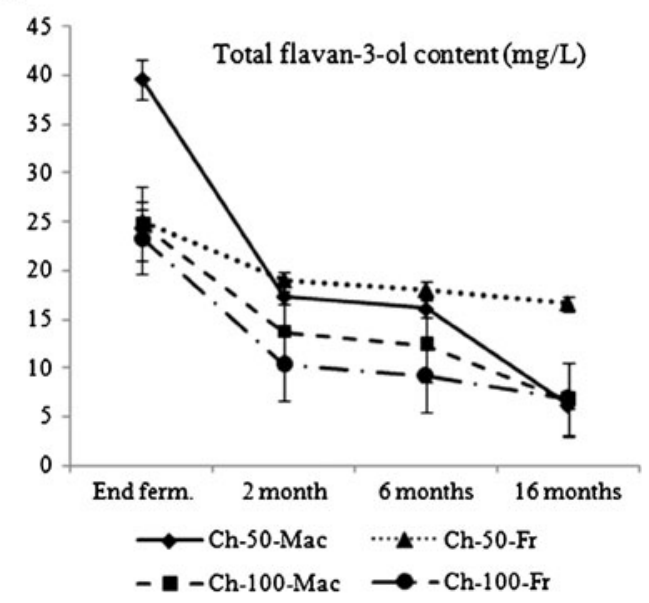

Fig. 2 Changes of a total phenolics, b total flavonoids, and $\mathbf{c}$ total flavan-3-ols in Chardonnay wines fermented with Macedonian and French yeast, containing 50 and $100 \mathrm{mg} / \mathrm{L}$ of $\mathrm{SO}_{2}$ during storage: after fermentation, after 2, 6, and 16 months. Error bars represent standard deviations. Ch, Chardonnay; Mac, Macedonian yeast; Fr, French yeast; $50-50 \mathrm{mg} / \mathrm{L} \mathrm{SO}_{2} ; 100-100 \mathrm{mg} / \mathrm{L} \mathrm{SO}_{2}$ 
Fig. 3 Principal component score plot (PC1 and PC2) of Smederevka and Chardonnay wines obtained under different vinification conditions and stored during 16 months, based on the spectrophotometric data for $\mathrm{TP}, \mathrm{TF}$, and $\mathrm{TF}_{3 \text {-ols. }} \mathrm{Ch}$, Chardonnay; Mac Macedonian yeast; $\mathrm{Fr}$ French yeast; 50$50 \mathrm{mg} / \mathrm{L} \mathrm{SO}_{2} ; 100-100 \mathrm{mg} / \mathrm{L}$ $\mathrm{SO}_{2}$

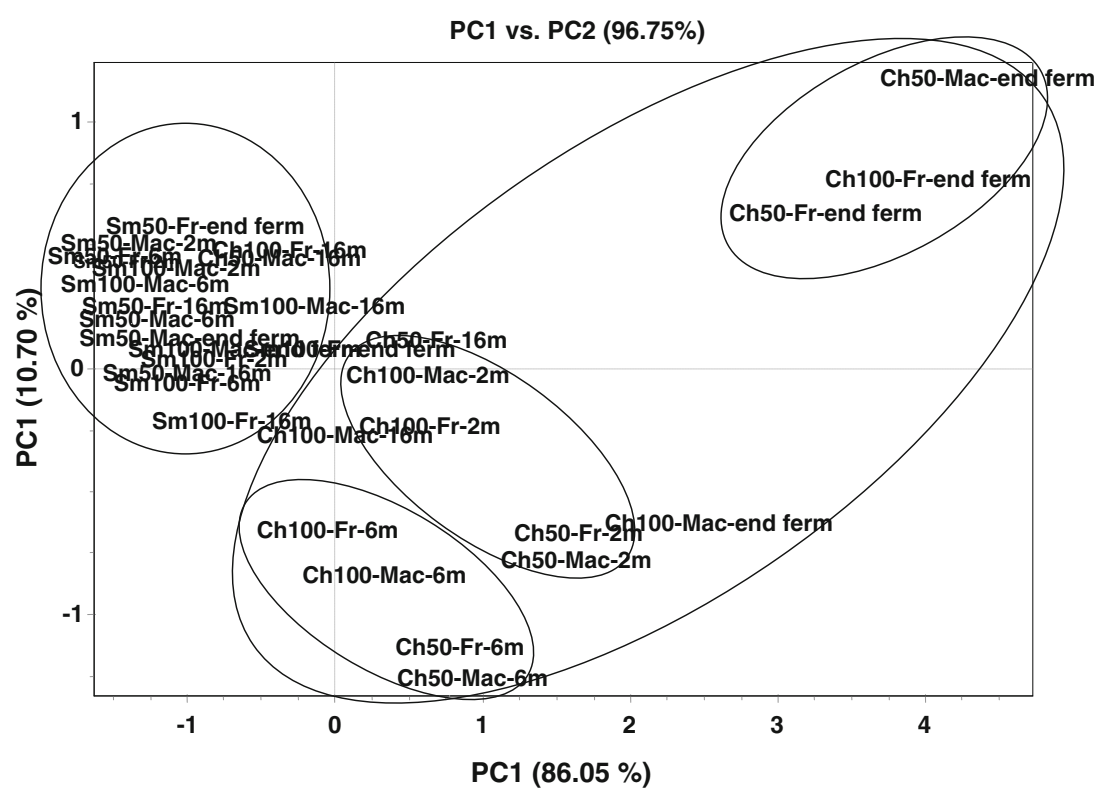

suggests adsorption of phenolic compounds to the yeast cell walls (Mazauric and Salmon 2005). Comparing the wines from both varieties fermented with the same yeast strain, no significant differences $(p>0.05)$ in the content of TP and $\mathrm{TF}_{3-\text { ols }}$ were found, except for Ch50 where a higher amount of $\mathrm{TF}_{3 \text {-ols }}$ was noticed in the wine vinified with Vinalco yeast (Table 2). The applied yeasts did not show a significant influence on the $\mathrm{TP}$ and $\mathrm{TF}_{3 \text {-ols }}$ probably because of their similar fermentation rates and/or their belonging to the same Saccharomyces cerevisiae species, which was in agreement with the previously published data for Merlot wines (Ivanova et al. 2009). On the other hand, Smederevka wines vinified with the Levuline yeast tended to contain a significantly higher amount of TF in comparison to wines fermented with Vinalco yeast (Table 2). This conclusion cannot be made for TF in the studied Chardonnay wines. Anyway, these differences in the content of TF could suggest that yeast can contribute to white wine phenolics, especially to the flavonoid level.

\section{Influence of Aging}

The amount of $\mathrm{TP}, \mathrm{TF}$, and $\mathrm{TF}_{3 \text {-ols }}$ in the studied Smederevka and Chardonnay wines have been determined in the following four phases: after fermentation, after 2, 6 , and 16 months. These results are presented in Figs. 1 and 2.

As stated in the literature (Kallithraka et al. 2009), the total phenolic content decreases during the wine aging. Thus, the content of TP for the wines from both varieties was decreasing significantly $(p<0.001)$ to the second month of storage (except for Sm50 wine), remaining stable till the sixth month of storage. Afterwards, the TP content increased in the Smederevka wines at the 16th month of storage (Fig. 1a), although this was not observed for Chardonnay wines. The higher final amount of TP could be a result of the increased content of caffeic, $p$-coumaric, and ferulic acids due to the possible hydrolysis of the esters of tartaric acids (caftaric, coutaric, fertaric) during storage. On the other hand, the decreased total phenolic content, observed in Chardonnay wines, is presumably a result of oxidation of the phenolic compounds such as flavonoids and flavan-3-ols, which are considered as significant contributors to the overall total phenolic content, and their degradation leads to changes of their content by loss of reactive hydroxyl groups (Singleton et al. 1999). The changes of flavan-3-ol monomers, (+)-catechin and (-)epicatechin lead to a decrease of TP with aging. Furthermore, benzoic acids, such as gallic acid, also decrease significantly during the storage period, contributing to the TP reduction. In addition, a formation of protein-tannin complexes has also been shown to contribute towards a decrease in phenolic content of white wine (Singleton et al. 1979; Betés-Saura et al. 1996).

With regard to the content of flavonoids in Smederevka and Chardonnay wines (Figs. $1 \mathrm{~b}$ and $2 \mathrm{~b}$ ), a significant

Table 3 Loadings of the features in the first three principal components for the analyzed Smederevka and Chardonnay wines

\begin{tabular}{lccc}
\hline & PC1 & PC2 & PC3 \\
\hline $\mathrm{TP}$ & 0.9115 & -0.3846 & -0.1456 \\
$\mathrm{TF}$ & 0.9017 & 0.4152 & -0.11201 \\
$\mathrm{TF}_{3 \text {-ols }}$ & 0.9682 & -0.0246 & 0.249 \\
$\%$ of variance & 86 & 11 & 3 \\
\hline
\end{tabular}


decrease in TF was observed up to the second month of storage, followed by a slight decrease till the sixth month. On the 16th month of storage, no significant differences $(p>0.05)$ between the flavonoid content of the wines aged from 6 to 16 months, from both varieties, were observed, even a slight increase (not significant, $p>0.05$ ) in the TF was measured in the Chardonnay wines. The decreased flavonoid content is probably a result of the oxidative degradation, precipitation, or hydrolysis of the flavonols (Zafrilla et al. 2003). The poorly soluble aglycones, formed as a result of hydrolysis, can also precipitate and contribute to the decrease of the total flavonoid content in wines.

The changes of the flavan-3-ols content followed a similar trend to the ones of the flavonoids. Thus, the content of $\mathrm{TF}_{3 \text {-ols }}$ significantly decreased till the second month $(p<0.001)$ in the wines from both varieties. Afterwards, they remained stable during storage (only a slight increase in Smederevka wines was observed but not significant, $p>0.05$ ). The reduction of flavan-3-ols in the white wines is affected by the oxidation and polymerization reactions of flavan-3-ols and procyanidins, which have a strong influence on the susceptibility of white wines to browning (Simpson 1982). Furthermore, the storage conditions affect the content of flavan-3-ols since they can undergo hydrolysis, oxidation, and complexation during aging (Zafrilla et al. 2003).

\section{Principal Component Analysis}

A principal component analysis has been applied on the results for $\mathrm{TP}, \mathrm{TF}$, and $\mathrm{TF}_{3 \text {-ols }}$ in order to discover the similarities and/or differences between the Smederevka and Chardonnay wines, and to evaluate if the parameters: variety, $\mathrm{SO}_{2}$, yeast, and time of aging could distinguish the studied white wines. The score plot of the first two PCs which account for $96.75 \%$ of the total variability of the wine samples shows a clear separation of Smederevka and Chardonnay wines (Fig. 3). Thus, the grouping of the samples was made mainly according to the variety: Chardonnay wines, mainly located in the positive part of PC1 (86.05\%) were clearly separated from the Smederevka wines, mainly located in the negative part of the PC1. As can be seen from Table 3, all three parameters TP, TF, and $\mathrm{TF}_{3-\text { ols }}$ contributing positively to $\mathrm{PC} 1$, are responsible for the varietal characterisation and differentiation of both cultivars. In fact, Chardonnay wines contain a higher content of these phenolic compounds in the all-studied aging phases. With regard to $\mathrm{PC} 2$, the grouping of the Chardonnay wines was observed according to the storage period. The wines analyzed after fermentation were placed in the positive part of $\mathrm{PC} 2$, which were well separated from the wines aged for 2 months and for 6 months (Fig. 3). As can be seen from Table 3, TF is the value with the highest contribution on the $\mathrm{PC} 2$, which means that the separation of the samples was performed according to the flavonoids in a correlation with storage time. No clear separation was observed for Smederevka wines during storage. In general, the grouping between the Smederevka and Chardonnay wines was performed as a result of the cultivar differences in $\mathrm{TP}, \mathrm{TF}$, and $\mathrm{TF}_{3 \text {-ols }}$ content. Furthermore, the separation of the Chardonnay wines was based mainly on the differences of the flavonoid content, decreasing in the wines during storage.

\section{Conclusions}

This study presents valuable data for the phenolic content of the white wines Smederevka and Chardonnay, produced under different treatments from grape varieties grown in the Republic of Macedonia, as well as useful information for the polyphenolic changes during aging in bottles. In general, the differences between Smederevka and Chardonnay wines were found in the higher content of $\mathrm{TP}, \mathrm{TF}$, and $\mathrm{TF}_{3 \text {-ols }}$ for Chardonnay wines probably attributed to the cultivarrelated differences. The higher amount of sulfur dioxide affected the higher content of total phenolics, flavonoids, and flavan-3-ols in the wines, while the yeast did not show a significant influence on TP and TF-ols, except on the content of TF. During storage, the content of TP was highest after fermentation, followed by a gradual decrease up to the second month, and remained stable till the sixth month of storage. The evolution trend of the total flavonoids and flavan-3-ols for the wines from both varieties was similar showing a gradual decrease of the content during wine aging.

\section{References}

Betés-Saura, C., Andrés-Lacueva, C., \& Lamuela-Raventós, R. M. (1996). Phenolics in white free run juices and wines from Penedès by high-performance liquid chromatography: changes during vinification. Journal of Agricultural and Food Chemistry, 44, 3040-3046.

Budić-Leto, I., \& Lovrić, T. (2002). Identification of phenolic acids and changes in their content during fermentation and ageing of white wines. Food Technology and Biotechnology, 40, 221-225.

Chamkha, M., Cathala, B., Cheynier, V., \& Douillard, R. (2003). Phenolic composition of Champagnes from Chardonnay and Pinot Noir vintages. Journal of Agricultural and Food Chemistry, 51, 3179-3184.

Cheynier, V., Rigaud, J., Souquet, J. M., Duprat, F., \& Moutounet, M. (1990). Must browning in relation to the behavior of phenolic compounds during oxidation. American Journal of Enology and Viticulture, 41, 346-349.

De Beer, D., Joubert, E., Gelderblom, W. C. A., \& Manley, M. (2005). Changes in the phenolic composition and antioxidant activity of Pinotage, Cabernet Sauvignon, Chardonnay and Chenin Blanc 
wines during bottle ageing. South African Journal of Enology and Viticulture, 26, 6-15.

Di Stefano, R., Cravero, M. C., \& Gentilini, N. (1989). Metodi per lo studio dei polifenoli dei vini (pp. 83-89). Maggio: L'Enotecnico I.

Hurtado, I., Caldú, P., Gonzalo, A., Ramon, J. M., Mínguez, S., \& Fiol, C. (1997). Antioxidant capacity of wine on human lowdensity lipoprotein oxidation in vitro: effect of skin contact in winemaking of white wine. Journal of Agricultural and Food Chemistry, 45, 1283-1289.

Ivanova, V., Vojnoski, B., \& Stefova, M. (2009). Assay of the phenolic profile of Merlot wines from Macedonia: effect of maceration time, storage, $\mathrm{SO}_{2}$ and temperature of storage. Macedonian Journal of Chemistry and Chemical Engineering, 28, 141-149.

Ivanova, V., Stefova, M., \& Chinnici, F. (2010). Determination of the polyphenol contents in Macedonian grapes and wines by standardized spectrophotometric methods. Journal of the Serbian Chemical Society, 75, 45-59.

Jeffery, D. W., Parker, M., \& Smith, P. A. (2008). Flavonol composition of Australian red and white wines determined by high-performance liquid chromatography. Australian Journal of Grape and Wine Research, 14, 153-161.

Kallithraka, S., Salacha, M. I., \& Tzourou, I. (2009). Changes in phenolic composition and antioxidant activity of white wine during bottle storage: accelerated browning test versus bottle storage. Food Chemistry, 113, 500-505.

Katalinic, V., Milos, M., Modun, D., Music, I., \& Boban, M. (2004). Antioxidant effectiveness of selected wines in comparison with (+)-catechin. Food Chemistry, 86, 593-600.

Lee, C. Y., \& Jaworski, A. W. (1987). Phenolic compounds in white grapes grown in New York. American Journal of Enology and Viticulture, 38, 277-281.

Mayén, M., Barón, R., Mérida, J., \& Medina, M. (1997). Changes in phenolic compounds during accelerated browning in white wines from cv Pedro Ximenez and cv. Baladi grapes. Food Chemistry, $58,89-95$.

Mazauric, J. P., \& Salmon, J. M. (2005). Interactions between yeast lees and wine polyphenols during simulation of wine aging: I. Analysis of remnant polyphenolic compounds in the resulting wines. Journal of Agricultural and Food Chemistry, 53, 5647-5653.

Mitić, M. N., Obradović, M. V., Grahovac, Z. B., \& Pavlović, A. N. (2010). Antioxidant capacities and phenolic levels of different varieties of Serbian white wines. Molecules, 15, 2016-2027.
Nevares, I., Del Alamo, M., Cárcel, L. M., Crespo, R., Martin, C., \& Gallego, L. (2009). Measure the dissolved oxygen consumed by red wines in aging tanks. Food and Bioprocess Technology, 2, 328-336.

Okamura, S., \& Watanabe, M. (1981). Determination of phenolic cinnamates in white wine and their effect on wine quality. Agricultural and Biological Chemistry, 45, 2063-2070.

Rayne, S., Sheppard, S., Di Bello, T., Eggers, N.J. (2008). Chromatic characteristics and optically derived compositional descriptors of micro-oxygenated wines from Vitis vinifera cv. Merlot and Cabernet Sauvignon. Food and Bioprocess Technology. doi:10.1007/s11947-008-0152-0 (in press).

Salacha, M. I., Kallithraka, S., \& Tzourou, I. (2008). Browning of white wines: correlation with antioxidant characteristics, total polyphenolic composition and flavanol content. International Journal of Food Science and Technology, 43, 1073-1077.

Simpson, R. F. (1982). Factors affecting oxidative browning of white wine. Vitis, 21, 233-239.

Singleton, V. L., \& Cilliers, J. J. L. (1995). Phenolic browning: a perspective from grapes and wine research. In C. Y. Lee \& J. R. Whitaker (Eds.), Enzymatic browning and its prevention (ACS Symposium Series No. 600, pp. 23-48). Washington, DC: American Chemical Society.

Singleton, V. L., Trousdale, E., \& Zaya, J. (1979). Oxidation of wines I. Young white wines periodically exposed to air. American Journal of Enology and Viticulture, 30, 49-54.

Singleton, V. L., Orthofer, R., \& Lamuela-Raventos, R. M. (1999). Analysis of total phenols and other oxidation substrates and antioxidants by means of Folin-Ciocalteu reagent. Methods in Enzymology, 299, 152-178.

Slinkard, K., \& Singleton, V. L. (1977). Total phenol analysis: automation and comparison with manual methods. American Journal of Enology and Viticulture, 28, 49-55.

Zafrilla, P., Morillas, J., Mulero, J., Cayuela, J. M., Martínez-Cachá, A., Pardo, F., et al. (2003). Changes during storage in conventional and ecological wine: Phenolic content and antioxidant activity. Journal of Agricultural and Food Chemistry, 51, 4694-4700.

Zhishen, J., Mengeheng, T., \& Jianming, W. (1999). The determination of flavonoid contents in mulberry and their scavenging effects on superoxide radicals. Food Chemistry, $64,555-559$. 